\title{
A Study of Supportive Policies on College Students in Innovation and Entrepreneurship
}

\author{
Yuxuan Zhang \\ School of Business, Jianghan University, Wuhan, P. R. China \\ 452048047@qq.com
}

Keywords: college students, employment, innovation and entrepreneurship

\begin{abstract}
Innovation and entrepreneurship, the hot issue in the context of new era, is right at the rapid development. How to utilize entrepreneurship to promote employment effectively, how to utilize entrepreneurship to boost innovation subtly, and how to utilize innovation to stimulate entrepreneurship are worth exploring. Based on college students, the paper discusses the status quo of innovation and entrepreneurship in China and puts forward the policy suggestions on supporting college students in innovation and entrepreneurship.
\end{abstract}

\section{Introduction}

With the expansion of the scale of higher education, millions of college students graduate annually. However, the limited positions are far unable to meet the enormous crowds of college students. According to statistics, the number of graduates in China has reached 7.56 million in 2016, and it is estimated that the number will reach 7.95 million in 2017. Downward pressure on China's economy has continued to mount, and the situation of obtaining employment is becoming increasingly severe $(\mathrm{Xu}, 2017)$ [1]. Entrepreneurship, as a new form of employment, provides an opportunity for dealing with the difficulties in job hunting for college students. Chinese Premier Li Keqiang delivered a speech at the opening ceremony of the Annual Meeting of the New Champions 2014, also known as the Summer Davos Forum and put forward the idea of massive wave of entrepreneurship by the people and at the grassroots level. To utilize entrepreneurship to promote employment shows an increasing trend. However, how the college students start entrepreneurship becomes a new challenge.

Entrepreneurship, also as a new form of innovation, provides an opportunity for coping with the problem of the lack of innovation elements for the country. Chinese Premier Li Keqiang delivered the Report on the Work of the Government at the Third Session of the 12th National People's Congress on March 5, 2015 and put forward the idea of mass entrepreneurship and innovation. However, how can the college students better achieve breakthroughs in innovation during the process of creating wealth? Innovation, as a new form of entrepreneurship, provides an opportunity for surmounting the problems of entrepreneurship homogeneity for college students. During the finals of first National "Internet+" I\&E Competition, Chinese Premier Li Keqiang pointed out that college students are the main force of implementing the strategy of innovation-driven development and promoting innovation and entrepreneurship. However, the problem is how to help college students improve the creative thinking and creativity and boost the awareness of entrepreneurship (Cheng, 2016) [2].

Implementing the strategy of innovation and entrepreneurship in college students corresponds with the development of the society. However, the lack of innovative thinking and awareness of entrepreneurship, uneven comprehensive quality and ability, imperfection in policies on innovation and entrepreneurship, and other factors play an exceedingly important role in the implementation of the strategy of innovation and entrepreneurship. Therefore, how the central government and local governments at all levels, social organizations, and colleges and universities, support college students in innovation and entrepreneurship is worth exploring. 


\section{Entrepreneurship, employment and innovation}

\subsection{Entrepreneurship promotes employment}

With the constant development of social economy, colleges and universities are open to students. The expansion of enrollment has been the primary strategy for colleges and universities to cultivate talents since 1999. On the one hand, it offers intellectual support for the advancement of society and makes it possible to deliver high-quality talents continuously. On the other hand, the number of college graduates shows an increasing trend and it is the new challenge for millions of graduates to obtain employment annually. The positions that enterprises and institutions offer are limited after all and thus unable to meet the needs, which is nothing new now. As a consequence, enterprises and institutions have to raise the standards of selecting talents, which in turn results in the fact that more and more college students have no choice to face the increasingly fierce competitions in job hunting even without job vacancies after graduation. In the meantime, affluent 2nd generation and the officiallings are actually rare and the college students without any trouble in job hunting are quite few. Therefore, maintaining one's independence, initiative and self-reliance is still the mainstream of social development. However, the phenomenon that graduates are unemployed, kept waiting for jobs at home, and even immersed in joy emerges in an endless stream. Meanwhile, graduation means unemployment for a majority of graduates, which mirrors the reality.

Statistics from the Ministry of Education show that the number of graduates in China is projected to reach 7.95 million in 2017, more than 0.3 million in 2016 (Xiong, 2017) [3]. In the meantime, official figures show that the number of graduates in China has been climbing. There were only 1.14 million graduates in 2001, and an increase of 6.51 million was witnessed during the 15 years.

College students' employment, as an essential part in social employment, goes hand in hand with social stability and economic progress. In order to fit with the status quo of rapidly growing economies and reduce the pressure of employment resulted from limited positions and increasing graduates, college students are encouraged to start their own business for self-employment. On the one hand, college students are not alone and more often cooperate with others when starting entrepreneurship, therefore, the entrepreneurial team is right formed and the employment effect promoted by entrepreneurship is self-evident. On the other hand, when college students start entrepreneurship, it is also necessary to recruit employees, which means more people can be employed. In the meantime, if someone succeeds in entrepreneurship, the interest and attention of the public can be aroused by the successful case, which makes it possible to engage more and more people in entrepreneurship, thus, promoting employment. From this, jobs show an upward spiral and the nature of entrepreneurship is to promote employment using multiplier effect (Zhu and Bao, 2016) [4]. The calling for entrepreneurship, therefore, emerges as the times require. And the voices of mass entrepreneurship and grassroots entrepreneurship are increasingly louder. Hence, it is no wonder that entrepreneurship is one of the biggest concerns for the country and society. As the key group in employment, fresh graduates start entrepreneurship to achieve self-employment, which ensures the employment rate to remain stable to some extent under the downward pressure on China's economy. And encouraging college students to start innovation and entrepreneurship has been regarded as an indirect route to deal with employment issues, the important foundation for expanding employment channels and achieve employment in high quality and the significant engine of fostering new growth areas and enhancing the vitality of economic development.

\subsection{Entrepreneurship boosts innovation}

Innovation sustains the progress of a nation and it is an inexhaustible motive force for the prosperity of a country, which is of paramount significance in all aspects. However, college talents lack the ability of innovation and entrepreneurship due to the imperfection in education system. Elementary education and secondary education are generally recognized as precollege education, which includes primary education, junior high school education and senior high school education. Elementary education and secondary education are results-oriented, seeking the common ground and homogeneous answers under the unified standard. During the period, thoughts are limited to a large 
extent and students are simply equipped with some basic skills. At this time, innovative thinking is a river without headwaters or a tree without roots. However, innovative ability is rooted in innovative thinking. Without innovative thinking, no innovative ability can be developed. On the other hand, higher education is generally recognized as college and post college education. Higher education is process-oriented, seeking diversified answers under the flexible standard. Therefore, the period of higher education helps develop dissimilated thoughts, and innovation is aimed at pursuing novelty. Furthermore, higher education is absolutely the cradle of innovative thinking.

College students, as the subjects of receiving higher education, have natural advantages. Humans are the most critical factor in innovation and the essence of innovation-driven is talent-driven. After education for more than 10 years, college students are armed with relatively full professional knowledge and sound personality. And professional knowledge offers intellectual support for innovation. In the meantime, college students, who are optimistic about future, full of youthful spirit, own great innovation spirit, on account of being young. And innovation spirit offers spiritual impetus for innovation. Furthermore, college students own great advantages in integrating resources in and out of campus owing to living in the campus environment. And resource integration offers material basis. Last but not least, college students are eager for putting theories that have been learnt into practice because of long-term exposure to professional knowledge. And practical application offers target guarantee for innovation.

Entrepreneurship is the process of pursuing, integrating, utilizing and exploiting various resources to create value, not rigidly adhered to the limitation of resources at present (Zhu, 2010) [5]. Narrowly speaking, entrepreneurship falls under the category of economics, and entrepreneurship is an economic activity where subjects offer products and services for the society through establishing certain forms of business organization with the aim of creating value and employment opportunities. In nature, entrepreneurship is the process of growing out of nothing. Therefore, entrepreneurship boosts innovation, which is undoubtedly an effective means of promoting innovation. Confronted with fierce competitions of employment, college students must consider how to gain a foothold in the society. Mass entrepreneurship and innovation, as part of China's national economic strategy, provides an opportunity for college students beyond doubt. And during the process of entrepreneurship, business subjects will come up with some innovative ideas and motivations intentionally or unintentionally or subjectively or objectively, because enterprises are the economic organizations for profit orientation and the ultimate goal of them is to maximize revenues and profits, and business subjects will definitely make constant adjustments to business strategy, marketing model, personnel structure and so forth in operation based on practical conditions. At this time, innovation sprouts tangibly and intangibly.

On the basis of the difficulties in job hunting, encouraging college students to start entrepreneurship is an effective way of exploiting their natural advantages, which is an essential measure in promoting social innovation and economic development, utilizing entrepreneurship to boost innovation.

\subsection{Innovation stimulates entrepreneurship}

Mass entrepreneurship and innovation. And College students are the main force of implementing the strategy of innovation-driven development and promoting innovation and entrepreneurship. The census data shows that the proportion of college students who start self-entrepreneurship after graduation in China continues to rise. Entrepreneurship within college students is in full swing now.

However, with the clarion call for entrepreneurship sounding, bottlenecks in entrepreneurship started by college students have been increasingly emerging. Entrepreneurship programs, such as delivering takeaway food, working in electronic commerce, designing WeChat official accounts and so forth, are nothing new, which leads to serious homogenization. And most of them are the types of survivors, imitators and knockoffs, lacking innovation and originality. On the one hand, high product homogeneity leads to fierce competitions in similar industry, which ultimately evolves into price wars. On the other hand, the lack of innovation elements contributes too little to economic 
development in that innovation is an inexhaustible motive force for the development of human society. In the long term, homogeneous entrepreneurship programs are doomed to failure. And college students will suffer a great loss and being unemployed again. More importantly, college students will be discouraged. Hence, as time goes by, the disadvantages of entrepreneurship without innovation are continuously emerging, which eventually is hard to gain a foothold in the market.

Innovation stimulates entrepreneurship as the times require. Innovation is the process of conceptualization, characterized by new thoughts, new inventions and new descriptions. It is rooted in Latin and the original meaning includes three layers, that is, updating, inventing and changing ( $\mathrm{Yu}$, 2012) [6]. Therefore, innovation does not necessarily mean to make something out of nothing. And it is not as difficult as climbing up to heaven for college students to start entrepreneurship for innovation. At this time, encouraging entrepreneurship based on innovation is imperative. On the one hand, college students have the potential of innovation on account of their natural advantages. And they are definitely the excellent sources of talents in innovation and entrepreneurship, when confronted with the difficulty in job hunting. Furthermore, innovation is the soul of entrepreneurship, and if out of touch with innovation, entrepreneurship cannot be started well and competent in the market due to serious homogenization. Specifically, WeChat official accounts got preliminary development several years ago, and nowadays, the platforms are increasingly perfecting with the advancement of technology. However, a great number of college students right now are devoted to designing the accounts. And the lack of innovation elements and the compelling advantage to technology forms the ones which are almost the same. However, the core of the platform lies in attention and the advertising revenue can be achieved by product placement of advertisers, as a result of which, the new platforms are less likely to have any advantages when compared with forerunners. On the other hand, innovation is the soul of a nation's progress and an inexhaustible motive force for a country's prosperity. And mass entrepreneurship and innovation, which pursues innovation with brainstorming. College students, as the subjects of innovation, should fully exploit their natural advantages to innovation, which is an essential measure in promoting social innovation and economic development, utilizing entrepreneurship to boost innovation, which offers intellectual support for the advancement of social economy. Encouraging innovation to stimulate entrepreneurship is an effective measure of integrating economic development and social stability.

On the basis of the difficulties in job hunting, encouraging college students to start entrepreneurship based upon innovation is an effective way of exploiting their natural advantages, which is an essential measure in promoting social innovation and economic development, utilizing innovation to stimulate entrepreneurship.

\section{The status quo of innovation and entrepreneurship in China}

Mass entrepreneurship and innovation. And College students are the main force of implementing the strategy of innovation-driven development and promoting innovation and entrepreneurship. College students still have to face some obstacles that cannot be neglected when starting entrepreneurship, although a great number of preferential policies on college students in innovation and entrepreneurship have been introduced, and they actually own some advantages.

\subsection{College students lack innovative thinking and awareness of entrepreneurship}

College students are quick in though, but lack the way of innovative thinking. On the one hand, college students are increasingly imaginative and equipped with quick thinking, with more than 10 years of sedimentation of knowledge, accumulated experience and enough space. On the other hand, the fragmented knowledge results in the independence, gap and even irrelevance between the knowledge in that college students lack stereo knowledge view. And it is nothing new that college students see the trees but not the forest. The knowledge is viewed as isolated, static and unilateral, leading to the linear and two-dimensional thinking way and the lack of inflexibility and multi-dimensional when considering problems, as a result of necessary knowledge integration. Furthermore, college students follow almost the same pattern when surmounting problems. Under 
the circumstances, innovation is less likely to appear, and college students are bewildered when confronted with competitive and unpredictable markets.

College students are energetic, but lack the crisis awareness of entrepreneurship. The number of graduates in China has been increasing, and the positions that society offers are extremely limited. However, quite a few college students are indifferent to this, and even some of them who are blindly optimistic harbor the belief that there will always be their places for them. Nevertheless, the reality is that the gods send nuts to those who have no teeth and the college students without jobs or waiting for one at home can be found everywhere, the reason for which lies in that college students are overconfident and blindly optimistic, without the awareness of entrepreneurship. The essence of the awareness of entrepreneurship is the awareness of crisis which is indispensable for college students in that the social development is always full of unpredictable variables. And when faced with the difficulties in job hunting, the students who have the awareness of entrepreneurship will try every means to seek another way, otherwise, they will wait, complain and even resent.

\subsection{College students' uneven comprehensive quality and ability}

With the expansion of enrollment, higher education is increasingly popularizing. However, the quality of the students who are educated in different levels of colleges varies from each other. 985 Project and 211 Program have been finished and China is now in the phase of carrying out Double World-classes Program. The division of colleges, therefore, indicates the differences and gaps between them, let alone the differences in the quality of the students. Certain comprehensive quality and ability are the fundamental premises of starting innovation and entrepreneurship, albeit well-known colleges and high academic qualification are no long the only criterion for evaluating talents. For most entrepreneurs, it is the difficulties in job hunting or inappropriate job positions or inadequate qualifications for employing units or dissatisfaction with salaries and allowances or unwillingness to work for others that forces college students to start innovation and entrepreneurship. Of course, there are still quite a lot of students who show great passion for innovation and entrepreneurship and stick to the career from beginning to end. However, the entrepreneurship fruits are not the same owing to college students' uneven comprehensive quality and ability.

For the entrepreneurs who show the relatively lower quality and ability, they lack the systematic studying in relevant professional knowledge or are not fully devoted themselves to the major learning, as a result of which, they know so little about entrepreneurship and lack the overall understanding of industry, the ability to make the choice of the developing direction, the design concepts about products, services and business models, the leadership to build a high-efficient corporate team, ultimately leading to the big investment and low revenue, and even losing everything. This does not solve the problem of the difficulties in job hunting, and time, energy, and resources are wasted instead. For the entrepreneurs who show the relatively higher quality and ability, it is a good chance for them to make what they have learnt serve the practical purpose, to make the best use of what have been learnt, and to learn by practicing. They seize market opportunities, build the appropriate business models, strengthen social networks, and establish a proper corporate team, eventually achieving small investment and high revenue, which realizes the goal of self-employment and earning incomes, and makes it possible for offer positions to others for employment.

\subsection{Imperfection in policies on innovation and entrepreneurship}

College students are the main force of implementing the strategy of innovation-driven development and promoting innovation and entrepreneurship, which is as part of China's national economic strategy. And a great number of preferential policies on college students in financing, opening up, taxes, training and guidance of innovation and entrepreneurship and so forth have been introduced. However, there are still some imperfections in them.

a) Insufficient impetus to innovation and entrepreneurship education. Innovation and entrepreneurship education, as the core of innovation and entrepreneurship career, has not been fully paid great attentions by colleges. Nowadays, innovation and entrepreneurship education in college is still insufficient, albeit some improvements have been made. For most colleges, the course in 
innovation and entrepreneurship is set as an optional course with extremely limited teaching hours. Hence, college students are still confused about the concept of innovation and entrepreneurship. And they lack the awareness of innovation and entrepreneurship, and the comprehensive quality and ability.

b) Not fully implementing innovation and entrepreneurship policies. Nowadays, some policies have not completely been implemented, albeit some preferential policies on college students in innovation and entrepreneurship have been introduced. Still, a long period of time is needed to implement all the policies from national to local governments and to colleges. The long-period and hesitation result in insufficient impetus of college students to innovation and entrepreneurship and they take a wait-and-see attitude toward it.

c) Single subject in introducing innovation and entrepreneurship policies. Mass entrepreneurship and innovation, as part of China's national economic strategy, contributes to introducing supportive policies on innovation and entrepreneurship. However, the subject of developing policies is mainly as central government and local governments at all levels. And during innovation and entrepreneurship, college students undoubtedly need to encounter subjects other than governments. Therefore, governments at all levels should fully consider the ideas and suggestions of college students, colleges, banks and social organizations, when developing innovation and entrepreneurship policies, and effectively make use of the supporting measures introduced by these subjects, thus perfecting the supporting system of innovation and entrepreneurship policies.

\section{Supportive policies on college students in innovation and entrepreneurship}

The obstacles to systems still exist that restrict the development of innovation and entrepreneurship and a great number of supportive policies have not fully been implemented. Hence, supporting system of innovation and entrepreneurship policies needs further improvements. Central government and local governments at all levels, colleges, social organizations and college students are the four main subjects to supportive policies in innovation and entrepreneurship.

\subsection{Central government and local governments at all levels}

Central government and local governments at all levels should strengthen the force of policy research and create a favorable atmosphere of innovation and entrepreneurship. In the meantime, the governments are supposed to implement the support for college students in innovation and entrepreneurship and perfect the system of supervision, implementation and evaluation. Firstly, the nation should establish the sound supporting system of innovation and entrepreneurship, starting with capital, policies and articles to standardize the implementing policies on innovation and entrepreneurship to keep the openness and justice. For example, the procedure of college students' registering companies can be simplified and taxes on innovation and entrepreneurship of college students can be cut. Secondly, innovation and entrepreneurship education should be included in higher education. Other than traditional ideological and political education, professional education, practice exercise, research training, higher education should involve innovation and entrepreneurship education, aiming to cultivate the college students' innovation thinking and the awareness of entrepreneurship. Furthermore, the outstanding college students in innovation and entrepreneurship and excellent programs can be selected through holding competitions and establishing supportive funding and so forth. And the support of capital, technology and information should be strengthened to foster the students who are equipped with comprehensive quality and ability and the projects. Meanwhile, entrepreneurship mentors should be assigned to track the programs and offer guidance and advice on technology and information, striving to keep the entrepreneurs remaining stable during the startup period. Finally, the favorable atmosphere of innovation and entrepreneurship should be created and managed. College students, as the subjects of innovation and entrepreneurship, infuse new blood into the development of market economy. However, the market itself is competitive, central government and local governments at all levels should create the harmonious environments for innovation and entrepreneurship. Simultaneously, they are supposed to promote the 
communication and resource circulation between enterprises, thus contributing to circular economy (Jiang, 2015) [7].

\subsection{Colleges}

Colleges should cooperate with governments at all levels to implement the relevant policies and introduce some relevant documents. Firstly, colleges, as the students' carrier of receiving education, should attach importance to innovation and entrepreneurship education, which means to include it in the program of cultivating talents. Colleges should set up the general education curriculum of innovation and entrepreneurship, add some elective courses on it, establish the double major in it, and promote the judgement of the credits in it. In addition, colleges should hold the innovation and entrepreneurship training camps regularly, and arrange for the entrepreneurship mentors on campus to tutor the students, helping the students who own some ideas get to know the social environments and make the wise decisions. Meanwhile, colleges are supposed to introduce some mentors off campus to share resources. Secondly, colleges should enhance the training of the teachers in innovation and entrepreneurship to ensure their professionalism. Sometimes, renowned social scholars can be invited to guide the students to start innovation and entrepreneurship correctly and share the living examples relevant to it, helping students know the actual world more clearly and effectively avoid the risks that are inevitable during the process after graduation, which achieves high quality, high efficiency and sustainability of innovation and entrepreneurship. Furthermore, colleges should provide infrastructure for students in innovation and entrepreneurship. Colleges select excellent programs and support them in fund through holding competitions. Incubators should be established on campus to provide workplace for students and the necessities should be equipped with, such as computers and so forth. Meanwhile, some awards for students who start innovation and entrepreneurship should be set up, such as Innovation and Entrepreneurship Pioneers, to inspire them. Finally, colleges should promote the transformation of scientific and technological achievements of college teachers. It is an organic combination of scientific researches at university and market economy, which forms the system where college teachers are the subjects of scientific research and college students are the subjects of operation, bringing the origins of science innovation and the pioneers of market operation together.

\subsection{Social organizations}

Apart from central government and local governments at all levels, colleges, social organizations, as important parts in the society, undoubtedly are of paramount significance in supporting college students in innovation and entrepreneurship. Firstly, social organizations, such as some enterprise service associations, business incubators, group innovation space and so forth, regularly hold innovation and innovation and entrepreneurship training camps, salons and other learning activities, which helps build the platforms of learning and communicating, providing college students with effective guarantees for learning. Secondly, social organizations can march to colleges, which promotes the combination of colleges' resources and social resources and offers the latest news and policies on innovation and entrepreneurship, providing college students with effective guarantees for social information. Furthermore, social organizations can start the activities of seeking pioneers and stars in innovation and entrepreneurship, and publicize and promote them by virtue of newspapers, new media platforms and so forth, providing college students with effective guarantees for promotion. Finally, there is no lack of successful enterprises in social organizations. And they can combine their development, searching for the potential, motivated and energetic college students and supporting them appropriately.

\subsection{College students}

As the subjects of innovation and entrepreneurship, college students can support themselves, which is promising. Firstly, college students should intensify the learning of innovation and entrepreneurship. Receiving innovation entrepreneurship education, knowing its status quo and being equipped with comprehensive quality and ability lay a solid practicing foundation for starting innovation and entrepreneurship henceforth. Secondly, college students should seek for and integrate resources. Enterprises are the economic organizations for profit orientation and they cannot achieve profits without resources. However, resources are limited and they are absolutely invaluable for 
enterprises. College students, studying in colleges, can link the resources on campus and off campus, which provides strong guarantee for them. During the period of living on campus, college students cannot only participate in various student organizations, associations but they can also take internships and part-time jobs off campus to develop social networks. And the social network, as a scarce resource, lays the favorable foundation for creating wealth in the future, which means that social network is the wealth. Finally, college students should strengthen their conviction in that innovation and entrepreneurship will not proceed without a hitch. Innovation means sword Zoupian front and being born of fire. In the meantime, entrepreneurship means being smashed to pieces and a slim chance of surviving. Therefore, college students should give full play to the subjective initiative and be equipped with the spirit of hardship, indomitable effort, and self- reliance. Also, they should develop their own talents and improve the quality and ability comprehensively. And they should stick to the belief, follow the inspiring value, and encourage themselves that they will succeed one day.

\section{Conclusion}

Innovation and entrepreneurship, the hot issue in the context of new era, is right at the rapid development. Central government and local governments at all levels, colleges and social organizations show great about innovation and entrepreneurship because of its economic and social significance. Innovation and entrepreneurship has gone through three critical phases - entrepreneurship promotes employment, entrepreneurship boosts innovation and innovation stimulates entrepreneurship.

\section{Acknowledgement}

The paper is supported by the fund of scientific research: Supportive Policies on College Students in Entrepreneurship (Project No.2016zd005). Thanks for the supporting of School of Business of Jianghan University. In the meantime, I would like to extend the sincere gratitude to the supervisors, Liu Quanhong, Zheng Qiong and Chen Jun, for their instructive advice and useful suggestions on the thesis.

\section{References}

[1] J. Xu, "The study on the system of talents training mechanism of Internet Plus in high vocational colleges”, Management Observer, 2017 (13): 133-135.

[2] K. Cheng, "The study of establishing trinity platforms for college students in entrepreneurship”, Knowledge Library, 2016 (17): 40.

[3] B. Xiong, "Employment subsidies are not beneficial to breaking the theory of Only Qualification”, Human Resource Development, 2017 (7): 78-78.

[4] Y. Zhu and T. Bao, "The effects of employment promoted by college students' entrepreneurship and countermeasures, China Market, 2016 (20): 231-232.

[5] X. Zhu, "A study of the countermeasure for the development of entrepreneurial culture in Shan Dong”, Modern Enterprise Education, 2010 (15): 88-89.

[6] Y. Yu, "The guidance of innovation culture on continuing education of college teachers", Education and Cultivation, 2012 (18): 26-27.

[7] X. Jiang, "A brief probe into the situation and policy on innovation and entrepreneurship", Science and Technology Innovation Herald, 2015 (26): 239-240. 